Vol 5 No 1 (2022) 96-114 P-ISSN 2620-295 E-ISSN 2747-0490 DOI: 1047467/elmal.v5i1.639

\title{
Pengaruh Motivasi Kerja dan Lingkungan Kerja Islami terhadap Kinerja Karyawan pada Bank Syariah Indonesia KCP Bogor Pomad
}

\author{
Bagja Hidayah', M. Kholil Nawawi², Syariah Gustiawati ${ }^{3}$ \\ 1,2,3 Universitas Ibn Khaldun Bogor, Jawa Barat, Indonesia \\ bagjahidayah26@gmail.com¹, kholil@fai.uika-bogor.ac.id², \\ syarifah@fai.uika-bogor.ac.id ${ }^{3}$
}

\begin{abstract}
ABSTRACK
In the world of work of a company, there are many supporting aspects that support the running of a company, for example, employees. These things need to be considered so that the achievement of goals in the company can run well, by paying attention to motivation and an Islamic work environment that is expected to increase enthusiasm at work. In order to achieve these goals, employees need to be given the right motivation and Islamic work environment in order to have high performance so that they can provide maximum service to the community. This research uses quantitative methods and data collection techniques. The research is carried out by distributing questionnaires to employees of Bank Syariah Indonesia KCP Bogor Pomad which will then be used as samples. The results showed that the significant value for the effect of work motivation on employee performance was 0.02 and the significant value of the Islamic work environment variable on employee performance was 0.00 . This means that the $\mathrm{X} 1$ and $\mathrm{X} 2$ variables have an influence on the Y variable.
\end{abstract}

\section{Keywords: Work motivation, Islamic work environment, employee performance}

\begin{abstract}
ABSTRAK
Dalam dunia kerja suatu perusahaan banyak sekali aspek penunjang yang mendukung berjalannya suatu perusahaan antara lain contohnya adalah karyawan,. Hal-hal tersebut perlu sekali diperhatikan agar pencapaian tujuan dalam perusahaan dapat berjalan dengan baik, dengan memperhatikan motivasi dan lingkungan kerja yang islami diharapkan dapat menambah semangat dalam bekerja. Agar dapat mencapai tujuan tersebut, karyawan perlu diberikan motivasi dan lingkungan kerja islami yang tepat agar memiliki kinerja yang tinggi sehingga dapat memberikan pelayanan kepada masyarakat secara maksimal. Penelitian ini menggunakan metode kuantitatif dan teknik pengumpulan data penelitian dilakukan dengan cara penyebaran kuisioner kepada karyawan Bank syariah Indonesia KCP bogor pomad yang selanjutnya akan dijadikan sampel. Hasil penelitian menunjukkan bahwa nilai significan untuk pengaruh motivasi kerja terhadap kinerja karyawan adalah sebesar 0,02 dan nilai significan variabel lingkungan kerja islami terhadap kinerja karyawan sebesar 0,00. Artinya variabel X1 dan X2 memiliki pengaruh terhadap variabel Y.
\end{abstract}

Kata kunci: Brand Image, kualitas pelayanan, keputusan menabung

\section{PENDAHULUAN}




\section{Vol 5 No 1 (2022) 96-114 P-ISSN 2620-295 E-ISSN 2747-0490 DOI: 1047467/elmal.v5i1.639}

Islam sebagai sistem kehidupan yang universal, integral, dan komprehensif telah menetapkan tatanan yang utuh untuk kehidupan manusia. Sebagai way of life, Islam menata berbagai hal yang berkaitan dengan kehidupan, dari hal yang paling sederhana hingga urusan yang paling rumit sekalipun. Baik dalam aspek politik, ekonomi, pendidikan, seni, sosial, budaya, dan sebagainya. Islam adalah agama yang sempurna, yang mengatur hal yang bersangkutan dengan ekonomi. Apabila perekonomian suatu negara menerapkan dasar Al-Quran dan Hadist sebagai dasar penerapannya, tentunya suatu perekonomian nasional akan berjalan dengan baik dan terarah sesuai aturan (Fitria, 2016)

Di Indonesia, perkembangan pembelajaran dan pelaksanaan ekonomi islam juga telah mengalami perkembangan yang sangat pesat. Saat ini indonesia terdapat lembaga keuangan yang salah satunya adalah perbankan. Bank berusaha untuk memajukan teknologi-informasi agar-dapatmemberikan tenaga kerja yang berkualitas, sumber daya manusia mempunyai peranan penting dalam suatu organisasi atau perusahaan termasuk Perbankan Syariah. Sebagai penggerak dalam organisasi, karyawan juga memiliki kebutuhan, keinginan, dan dorongan yang diharapkan dari perusahaan. Harapan ini adalah motivasi, dimana jika harapan ini tidak terpenuhi, maka-akan muncul keluhan yang lambat laun dapat mengakibatkan perusahaan-yang berdampak pada kinerja yang dihasilkan. (Maguni \& Maupa, 2018)

Ada beberapa hal yang dapat mempengaruhi-kinerja-karyawan, oleh karena itu perusahaan harus berusaha-menjamin agar-faktor-yang berkaitandengan kinerja dapat dipenuhi secara-maksimal, salah satu faktor yang mempengaruhi adalah motivasi dan lingkungan kerja. Agar-dapat mencapaitujuan tersebut-karyawan perlu diberikan motivasi dan lingkungan kerja islami yang tepat agar memiliki kinerja yang tinggi sehingga dapat memberikan pelayanan kepada masyarakat secara maksimal. Idealnya, setiap karyawan memiliki kinerja yang tinggi sehingga dapat memberikan pelayanan kepada masyarakat secara maksimal

\section{TINJAUAN TEORITIS DAN HIPOTESIS}

\section{Pengertian Motivasi Kerja}

Motivasi.berasal dari kata.latin movere yang.berarti dorongan.atau menggerakkan. Motivasi (motivation) dalam manajemen hanya ditujukan 


\section{Vol 5 No 1 (2022) 96-114 P-ISSN 2620-295 E-ISSN 2747-0490 DOI: 1047467/elmal.v5i1.639}

pada sumber daya manusia.umumnya dan bawahan khususnya.Motivasi mempersoalkan bagaimana caranya.mengarahkan daya dan.potensi bawahan, agar.mau bekerja sama secara.produktif berhasil mencapai.dan mewujudkan tujuan.yang telah ditentukan. Pentingnya.motivasi karena motivasi.adalah hal yang menyebabkan, menyalurkan dan.mendukung perilaku.manusia, supaya mau.bekerja giat dan antusias.mencapai hasil yang.optimal. Motivasi semakin.penting karena.manajer membagikan pekerjaan.pada bawahannya.untuk dikerjakan.dengan baik.dan terintegrasi.kepada tujuan.yang diinginkan (Farida umi, 2015, p. 24)

\section{Tujuan Motivasi Kerja}

Pada hakikatnya.pemberian motivasi.kepada pegawai.tersebut mempunyai tujuan.yang dapat.meningkatkan berbagai.hal, Terdapat beberapa tujuan motivasi menurut Hasibuan (2010:97) dalam (NiKurniasari, 2018) yaitu:
a) Mendorong gairah dan semangat kerja karyawan
b) Meningkatkan moral dan kepuasan kerja karyawan
c) Meningkatkan produktivitas kerja karyawan
d) Mempertahankan loyalitas dan kestabilan karyawan perusahaan
e) Meningkatkan kedisiplinan dan menurunkan tingkat absensi karyawan
f) Mengefektifkan pengadaan karyawan
g) Menciptakan suasana dan hubungan kerja yang baik 8. Meningkatkan kreativitas dan partisipasi karyawan
h) Meningkatkan kinerja karyawan

\section{Motivasi Kerja Dalam Perspektif Islam}

Mencari nafkah dalam islam adalah sebuah kewajiban. Islam adalah agama yang fitrah, yang sesuai dengan kebutuhan manusia, diantaranya adalah kebutuhan fisik. Salah satu cara memenuhi kebutuhan fisik itu ialah dengan bekerja. Motivasi kerja dalam islam bukanlah untuk mengejar hidup hedonis, bukan juga untuk status, apalagi mengejar kekayaan dengan segala cara. Dengan demikian, motivasi kerja islam bukan hanya untuk memenuhi nafkah semata tetapi sebagai kewajiban beribadah kepada Allah SWT setelah ibadah fardhu lainnya. Motivasi kerja islam adalah komitmen terkait pekerjaan yang berasal dari hubungan seorang karyawan dengan tuhannya (Rahman, 1995) dalam (Anoraga \& Prasetyo, 2015). 


\section{Vol 5 No 1 (2022) 96-114 P-ISSN 2620-295 E-ISSN 2747-0490 DOI: 1047467/elmal.v5i1.639}

\section{Pengertian Lingkungan Kerja Islami}

Lingkungan kerja yang dibutuhkan oleh setiap karyawan adalah lingkungan yang mendukung setiap usaha karyawannya, karna mayoritas karyawan di Bank Syariah Indonesia adalah agama Islam, maka harus terciptanya lingkungan kerja yang Islami karena keberadaan manusia di sekeliling untuk saling mengisi dan melengkapi satu dengan yang lainnya sesuai dengan perannya masing-masing dengan menjaga alam (lingkungan) dan makhluk ciptaan Allah yang lain. Yakni sebagai khalifah (pemimpin) yang harus menggunakan nilai-nilai syariat Islam dalam segala aktivitasnya, Allah telah menurunkan aturan syariat sistem sosial yang mengatur kehidupan manusia dalam politik, manajemen, sosial, ekonomi, yang sesuai dengan rahasia penciptaannya, yakni beribadah kepada Allah. ibadah inilah yang menjadi tujuan penciptaan manusia, sebagaimana Allah berfirman:

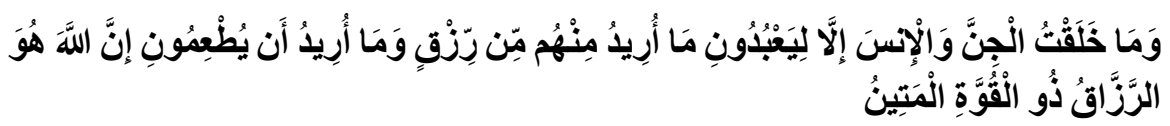

"Dan Aku tidak menciptakan jin dan manusia melainkan supaya mereka beribadah kepada-Ku. Aku tidak menghendaki rizki sedikit pun dari mereka dan Aku tidak menghendaki supaya mereka memberi makan kepada-Ku. Sesungguhnya Allah Dia-lah Maha Pemberi rizki Yang mempunyai kekuatan lagi sangat kokoh." [Adz-Dzaariyaat: 56-58].

\section{Manfaat Lingkungan Kerja Islami}

Manfaat lingkungan kerja adalah menciptakan gairah kerja, sehingga produktivitas dan prestasi kerja meningkat. Sementara itu, manfaat yang diperoleh karena bekerja dengan orang-orang yang termotivasi adalah pekerjaan dapat diselesaikan dengan tepat. Yang artinya pekerjaan diselesaikan sesuai standart yang benar dan dalam skala waktu yang ditentukan. Prestasi kerjanya akan dipantau oleh individu yang bersangkutan, dan tidak akan menimbulkan terlalu banyak pengawasan serta semangat juangnya akan tinggi. Lingkungan kerja yang baik yaitu lingkungan kerja yang kondusif. Ada banyak hal untuk menciptakan lingkungan kerja yang diinginkan namun yang pasti antara atasan atau pimpinan dan bawahan memiliki visi yang sama bagaimana lingkungan kerja tersebut memberikan rasa aman dan nyaman bagi setiap orang yang berada di dalamnya. Perusahaan peduli dan memperhatikan para karyawannya, demikian juga 
Vol 5 No 1 (2022) 96-114 P-ISSN 2620-295 E-ISSN 2747-0490 DOI: 1047467/elmal.v5i1.639

sebaliknya. Yang akhirnya bisa menimbulkan motivasi kerja karyawan dan kinerja karyawan

\section{Pengertian Kinerja Karyawan}

Kinerja tergantung pada kombinasi antara kemampuan, usaha, dan kesempatan yang diperoleh. Salah satu penentu kemajuan kinerja bisnis dan organisasi, tentu saja adalah kecakapan dalam mengelola kinerja para karyawan atau pegawainya. Dengan kata lain, pengelolaan kinerja karyawan yang cemerlang pasti akan mengantarkan sebuah organisasi bisnis ke jalan yang menghantarkan kejayaan

\section{Tujuan Penilaian Kinerja}

Tujuan diadakannya penilaian kinerja bagi para karyawan yang dapat kita ketahui menurut (Enny, 2019, pp. 116-117) Penilaian Kinerja mempunyai tujuan dan manfaat baik bagi organisasi maupun bagi pegawai, diantaranya yaitu:

a) Perfomance Improvement: yaitu memungkinkan pegawai dan manajer untuk membuat tindakan yang berhubungan dengan penilaian kinerja.

b) Compensation Adjustment: yaitu membantu para pembuat keputusan untuk menentukan siapa saja yang berhak menerima kenaikan gaji atau sebaliknya

c) Placement Decision: menentukan promosi, mutase, atau penurunan jabatan

d) Training and Development Needs: mengevaluasi kebutuhan pelatihan dan pengembangan bagi pegawai

e) Career Planning and Development: memandu untuk menentukan jenis karir dan pengembangan potensi yang dimiliki

f) Staffing Process Deficiencies: mempengaruhi prosedur perekrutan pegawai

g) Informational Inaccuracies and Job Design Error: membantu menjelaskan kesalahan yang terjadi

h) Equal Employment Opportunity: menunjukkan bahwa penempatan pegawai tidak ada diskriminasi

i) External Challenges: factor kinerja karyawan secara eksternal seperti keluarga, keuangan pribadi, dan sebagainya 
Vol 5 No 1 (2022) 96-114 P-ISSN 2620-295 E-ISSN 2747-0490 DOI: $1047467 /$ elmal.v5i1.639

Feedback: memberikan umpan balik bagi urusan kepegawaian maupun pegawai sendiri Penilaian kinerja merupakan salah satu fungsi dari manajemen sumber daya manusia, maka sudah seharusnyalah untuk dijalankan dengan sebaik - baiknya. 


\section{Vol 5 No 1 (2022) 96-114 P-ISSN 2620-295 E-ISSN 2747-0490 DOI: 1047467/elmal.v5i1.639}

\section{Kinerja Karyawan Menurut Perspektif Islam}

Menurut (Maguni \& Maupa, 2018) Kinerja merupakan tindakan tindakan atau pelaksanaan tugas yang telah diselesaikan oleh seseorang dalam kurun waktu tertentu dan dapat diukur. Mengapa harus melakukan penilaian kinerja diri, baik sebagai hamba maupun sebagai pekerja, karena Allah menyuruh kita untuk melakukan hal itu sebagaimana Allah berfirman:

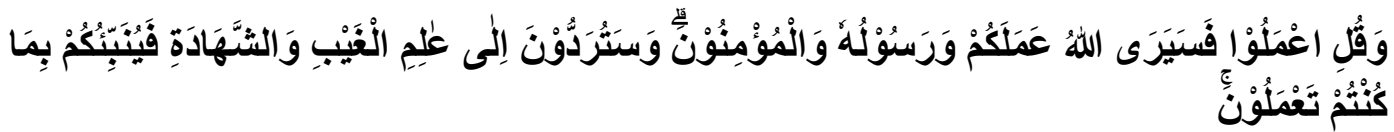

Dan katakanlah, "Bekerjalah kamu, maka Allah akan melihat pekerjaanmu, begitu juga Rasul-Nya dan orang-orang mukmin, dan kamu akan dikembalikan kepada (Allah) Yang Mengetahui yang gaib dan yang nyata, lalu diberitakanNya kepada kamu apa yang telah kamu kerjakan." QS At-taubah:105

Kata 'amalakum berarti amalmu atau pekerjaan. Kata ini bisa berarti "amalan di dunia yakni berupa prestasi selama di dunia". Dalam bahasa manajemen, hasil dari amalan atau pekerjaan itu adalah kinerja, performance. Jadi, ungkapan "sayarallâhu 'amalakum wa rasûluhû wal mu'minûn" sejatinya adalah pelaksanaan performance appraisal. Yang perlu diperhatikan, pengungkapan kata "Allah, Rasul, dan Mukmin" (yang dalam bahasa Arab menggunakan i'rab rafa', sebagai subjek), berarti para penilai itu tidak saja Allah, tetapi juga melibatkan pihak lain, yakni Rasul dan kaum Mukmin.

\section{METODOLOGI PENELITIAN}

Penelitian ini merupakan penelitian korelasional, korelasional merupakan suatu tipe penelitian yang bertujuan untuk mengetahui tingkat hubungan antara dua variabel(Andi Ibrahim, Asrul Haq Alang, Madi, Baharuddin \& Darmawati, 2018, p. 78). Penelitian ini menggunakan pendekatan kuantitatif, penelitian kuantitatif yakni adalah penelitian yang menjelaskan hubungan atau pengaruh yang terukur, meramalkan, dan mengontrol. Dengan pemahaman realita yaitu tunggal dan homogeny (Devi Abrista dan Tanjung Hendri, 2013, p. 74) Analisis kuantitatif pada penelitian ini digunakan untuk mengetahui Pengaruh motivasi kerja dan lingkungan kerja islami terhadap kinerja karyawan di Bank Syariah Indonesia KCP Bogor Pomad. Kemudian instrumen pengumpulan data pada penelitian ini menggunakan kuesioner. 
Vol 5 No 1 (2022) 96-114 P-ISSN 2620-295 E-ISSN 2747-0490 DOI: $1047467 /$ elmal.v5i1.639

\section{HASIL PENELITIAN DAN PEMBAHASAN}

Responden dalam penelitian ini adalah karyawan Bank Syariah Indonesia KCP Bogor Pomad, reponden penelitian ini mencakup beberapa karakteristik yang telah ditentukan peneliti, penelitian ini dikumpulkan melalui lembar kuesioner.

Responden dengan dengan kriteria usia, reponden yang berusia 21 tahun berjumlah 4 orang (11\%) dan untuk usia lebih dari 22 tahun berjumlah 26 orang $(89 \%)$. Responden yang paling mendominasi pada penelitian ini adalah responden berusia 20 dan 21 tahun.

Responden dengan dengan kriteria jenis kelamin laki laki dan perempuan dijadikan sebagai sampel penelitian. Reponden yang berjenis kelamin laki laki berjumlah 20 orang (57\%), sedangkan responden berjenis kelamin perempuan berjumlah 10 orang (43\%)

Uji Validitas dan Reliabilitas

Tabel 1 Uji validitas

\begin{tabular}{|c|c|c|c|c|}
\hline No. & Pernyataan & Rhitung $_{\text {Rtabel }}$ & Status \\
\hline 1. & $\mathrm{X} 1.1$ & 0,434 & 0,361 & Valid \\
\hline 2. & $\mathrm{X} 1.2$ & 0,469 & 0,361 & Valid \\
\hline 3. & $\mathrm{X} 1.3$ & 0,449 & 0,361 & Valid \\
\hline 4. & $\mathrm{X} 1.4$ & 0,641 & 0,361 & Valid \\
\hline 5. & $\mathrm{X} 1.5$ & 0,663 & 0,361 & Valid \\
\hline 6. & $\mathrm{X} 2.1$ & 0,512 & 0,361 & Valid \\
\hline 7. & $\mathrm{X} 2.2$ & 0,488 & 0,361 & Valid \\
\hline 8. & $\mathrm{X} 2.3$ & 0,714 & 0,361 & Valid \\
\hline 9. & $\mathrm{X} 2.4$ & 0,409 & 0,361 & Valid \\
\hline 10. & $\mathrm{X} 2.5$ & 0,375 & 0,361 & Valid \\
\hline 11. & $\mathrm{Y} 1$ & 0,421 & 0,361 & Valid \\
\hline 12. & $\mathrm{Y} 2$ & 0,616 & 0,361 & Valid \\
\hline 13. & $\mathrm{Y} 3$ & 0,659 & 0,361 & Valid \\
\hline 14. & $\mathrm{Y} 4$ & 0,369 & 0,361 & Valid \\
\hline 15. & $\mathrm{Y} 5$ & 0,490 & 0,361 & Valid \\
\hline
\end{tabular}

Tabel 2 hasil uji reabilitas

\begin{tabular}{|l|l|l|l|l|}
\hline NO & Variabel & $\mathbf{r}_{\text {alpha }}$ & $\mathbf{R}_{\text {tabel }}$ & Status \\
\hline
\end{tabular}


Vol 5 No 1 (2022) 96-114 P-ISSN 2620-295 E-ISSN 2747-0490 DOI: 1047467/elmal.v5i1.639

\begin{tabular}{|l|l|l|l|l|}
\hline 1 & Motivasi Kerja Kerja & 0,497 & 0,361 & Reliable \\
\hline 2 & $\begin{array}{l}\text { Lingkungan } \\
\text { Islami }\end{array}$ & $\begin{array}{l}\text { Reliable } \\
\text { Keputusan mahasiswa } \\
\text { menabung }\end{array}$ & 0,225 & 0,361 \\
\hline
\end{tabular}

Dari hasil uji validitas dan reliabilitas pada tabel diatas, dapat dilihat bahwa kuesioner yang digunakan merupakan kuesioner yang valid dan

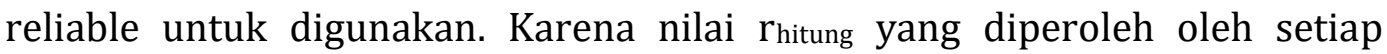
pernyataan itu lebih besar dari nilai $r_{\text {tabel }}$ yang ada yaitu 0,361 Begitupun dengan hasil uji reliabilitas pada tabel 2 tersebut, dimana hasil dari Cronbach's Alpha if item Deleted pada tabel tersebut memiliki nilai $\geq 0,6$. Itu artinya pernyataan atau kuesioner yang dibuat dinyatakan reliable

\section{Uji Normalitas Data}

a. Uji normalitas data digunakan untuk menguji data variabel bebas pada variable terikat apakah berdistribusi normal atau tidak. Uji normalitas pada penelitian ini menggunakan uji One Sample Kolmogrov-smirnov. Apabila nilai Asymp Sig. (2-tailed) lebih besar dari nilai signifikan dengan taraf 5\% atau 0,05 maka data tersebut dinyatakan terdistribusi normal.

Tabel 3 Hasil Uji Normalitas

One-Sample Kolmogorov-Smirnov Test

\begin{tabular}{|ll|r|}
\hline & & $\begin{array}{r}\text { Unstandardiz } \\
\text { ed Residual }\end{array}$ \\
\hline $\mathrm{N}$ & Mean & 30 \\
Normal Parameters $^{\mathrm{a}}$ & Std. Deviation & .0000000 \\
& Absolute & .99409551 \\
Most Extreme & Positive & .137 \\
Differences & Negative & .080 \\
& & .137 \\
Kolmogorov-Smirnov Z & .685 \\
Asymp. Sig. (2-tailed) & & .736 \\
\hline a. Test distribution is Normal. &
\end{tabular}


Vol 5 No 1 (2022) 96-114 P-ISSN 2620-295 E-ISSN 2747-0490 DOI: $1047467 /$ elmal.v5i1.639

One-Sample Kolmogorov-Smirnov Test

\begin{tabular}{|ll|r|}
\hline & & $\begin{array}{r}\text { Unstandardiz } \\
\text { ed Residual }\end{array}$ \\
\hline $\mathrm{N}$ & Mean & 30 \\
Normal Parameters & & .0000000 \\
& Std. Deviation & 1.99409551 \\
Most Extreme & Absolute & .137 \\
Differences & Positive & .080 \\
& Negative & -.137 \\
Kolmogorov-Smirnov Z & & .685 \\
Asymp. Sig. (2-tailed) & & .736 \\
\hline \multicolumn{2}{|c|}{} &
\end{tabular}

Berdasarkan tabel One Sample Kolmogrov-Smirnov pada tabel 4.10. diatas, diperoleh hasil nilai Asymp Sig. (2-tailed) pada responden pengikut autobase collagemenfess sebesar 0,493. Nilai yang diperoleh lebih besar dibandingkan dengan nilai signifikansi dengan taraf $5 \%$ atau 0,05 , ini artinya hasil dari uji normalitas dalam penelitian ini adalah berdistribusi secara normal.

b. Uji Multikolinearitas bertujuan untuk mengetahui apakah ada atau tidak korelasi antara variabel bebas dalam model regresi. Kemudian untuk mengetahui ada atau tidaknya multikolinearitas pada model regresi adalah dengan melihat nilai Tolerance dan VIF (Variance Inflation Factor). Nilai yang direkomendasikan untuk menunjukkan tidak adanya problem multikolinearitas adalah nilai Tolerance harus > 0,10 dan nilai VIF $<10$.

Tabel 4 Uji Multikolinearitas

\begin{tabular}{|l|l|c|c|}
\hline & \multicolumn{2}{|c|}{ Collinearity Statistics } \\
\hline \multicolumn{2}{|c|}{ Model } & Tolerance & VIF \\
\hline 1 & (Constant) & & \\
\hline & Motivasi Kerja $\left(\mathrm{X}_{1}\right)$ & .797 & 1.255 \\
\hline & Lingkungan Kerja Islami $\left(\mathrm{X}_{2}\right)$ & .797 & 1.255 \\
\hline
\end{tabular}


Vol 5 No 1 (2022) 96-114 P-ISSN 2620-295 E-ISSN 2747-0490 DOI: $1047467 /$ elmal.v5i1.639

a. Dependent Variable: Kinerja Karyawan (Y)

Berdasarkan tabel 4 diatas, dari hasil uji multikolinieritas dapat diketahui bahwa variabel brand image memiliki nilai VIF 1.255 dan tolerance 0,797, variabel motivasi kerja memiliki nilai VIF 1.255 dan tolerance 0.797 dan varibel kinerja karyawan memiliki nilai VIF 1.255 dan tolerance 0.797 . Yang artinya semua variabel bebas memiliki nilai TOL $>0,10$ dan nilai $\mathrm{VIF}<10$. Jadi, dapat disimpulkan bahwa dalam penelitian yang dilakukan ini terbebas dari masalah multikolinearitas.

\section{Uji Regresi Linear Berganda}

Uji regresi linear berganda digunakan pada penelitian ini ialah untuk menguji pengaruh antara variabel independen yaitu Pengaruh Motivasi kerja $\left(\mathrm{X}_{1}\right)$, dan Lingkungan kerja islami $\left(\mathrm{X}_{2}\right)$ secara bersama-sama dengan satu variabel dependen yaitu Kinerja karyawan (Y) dalam sebuah bentuk persamaan.

Tabel 5 Uji regresi linear berganda

\begin{tabular}{|l|l|c|c|}
\hline \multicolumn{2}{|l|}{} & \multicolumn{2}{c|}{ Unstandardized Coefficients } \\
\hline \multicolumn{2}{|l|}{ Model } & B & Std. Error \\
\hline & (Constant) & 12.255 & 5.899 \\
\hline & Motivasi kerja (X 1$)$ & .278 & .193 \\
\hline a. Dependent Variable: Kinerja karyawan (Y) & .206 & \\
\hline
\end{tabular}

Berdasarkan hasil tabel 5 analisis regresi linear berganda yang dilakukan melalui analisis Statistics dengan menggunakan Software SPSS Versi 


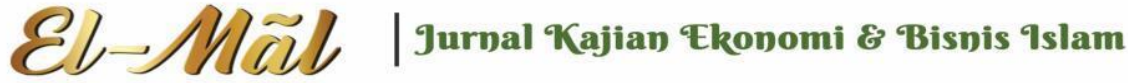

Vol 5 No 1 (2022) 96-114 P-ISSN 2620-295 E-ISSN 2747-0490 DOI: 1047467/elmal.v5i1.639

23, dengan memperhatikan angka yang berada pada kolom Unstandardzed Coefficients Beta. Maka dapat disusun persamaan regresi sebagai berikut:

$$
\mathrm{Y}=12.255+0.278 \mathrm{X}_{1}+0.206 \mathrm{X}_{2}
$$

1) Nilai konstanta sebesar 12.255, yang artinya apabila Motivasi Kerja $\left(\mathrm{X}_{1}\right)$ dan Lingkungan kerja islami $\left(\mathrm{X}_{2}\right)$ bernilai nol (0) maka Kinerja karyawan (Y) bernilai konstanta sebesar 12.255.

2) Jika nilai koefisien regresi variabel Motivasi kerja $\left(X_{1}\right)$ bernilai 0.278 yang berarti jika nilai variabel Motivasi kerja $\left(\mathrm{X}_{1}\right)$ mengalami kenaikan sebesar satu satuan sementara, maka Kinerja karyawan (Y) akan meningkat sebesar 0.278 dengan asumsi variabel lainnya tetap.

3) Jika nilai koefisien regresi variabel Lingkungan kerja islami $\left(\mathrm{X}_{2}\right)$ diperoleh nilai sebesar 0.206 yang berarti jika variabel Lingkungan kerja islami $\left(\mathrm{X}_{2}\right)$ mengalami kenaikan sebesar satu satuan sementara, maka Kinerja karyawan(Y) akan meningkat sebesar 0.206 dengan asumsi variabel lainnya tetap. 
Vol 5 No 1 (2022) 96-114 P-ISSN 2620-295 E-ISSN 2747-0490 DOI: $1047467 /$ elmal.v5i1.639

\section{Uji Korelasi}

Tabel 6 Uji korelasi

\section{Correlations}

\begin{tabular}{|c|c|c|c|c|}
\hline & & $\mathrm{X} 1$ & $\mathrm{X} 2$ & $\mathrm{y} 1$ \\
\hline \multirow[t]{3}{*}{$\mathrm{X} 1$} & $\begin{array}{c}\text { Pearson } \\
\text { Correlation }\end{array}$ & 1 & .090 & .579 \\
\hline & Sig. (2-tailed) & & .638 & .135 \\
\hline & $\mathrm{N}$ & 30 & 30 & 30 \\
\hline \multirow[t]{3}{*}{$\mathrm{X} 2$} & $\begin{array}{c}\text { Pearson } \\
\text { Correlation }\end{array}$ & .090 & 1 & .230 \\
\hline & Sig. (2-tailed) & .638 & & .221 \\
\hline & $\mathrm{N}$ & 30 & 30 & 30 \\
\hline \multirow[t]{3}{*}{ y1 } & $\begin{array}{c}\text { Pearson } \\
\text { Correlation }\end{array}$ & .279 & .230 & 1 \\
\hline & Sig. (2-tailed) & .135 & .221 & \\
\hline & $\mathrm{N}$ & 30 & 30 & 30 \\
\hline
\end{tabular}

Sumber data primer yang diperoleh, 2021.

Berdasarkan hasil data perhitungan Person correlation besarnya angka indeks hubungan antara variabel X dengan variabel Y adalah 0.579. jika dilihat dari table interprestasi yang diperoleh yaitu terletak pada interprestasi sedang dengan nilai antara 0.40-0.70

\section{Uji Hipotesis}

a. Uji T (Uji Parsial)

Uji T atau analisis parsial ini digunakan untuk mengetahui ada atau tidaknya pengaruh Variabel X secara parsial terhadap Variabel Y. untuk menentukan ada atau tidaknya pengaruh tersebut dengan melihat nilai dari signifikansi thitung tersebut. Apabila signifikansi $t>0,05$, maka tidak ada pengaruh antara Variabel X dengan Variabel Y. Begitupun sebaliknya apabila signifikansi $t<0,05$, maka ada ada pengaruh antara Variabel X dengan Variabel Y. 
Vol 5 No 1 (2022) 96-114 P-ISSN 2620-295 E-ISSN 2747-0490 DOI: $1047467 /$ elmal.v5i1.639

Tabel 9 Hasil Uji T

Coefficients $^{\mathrm{a}}$

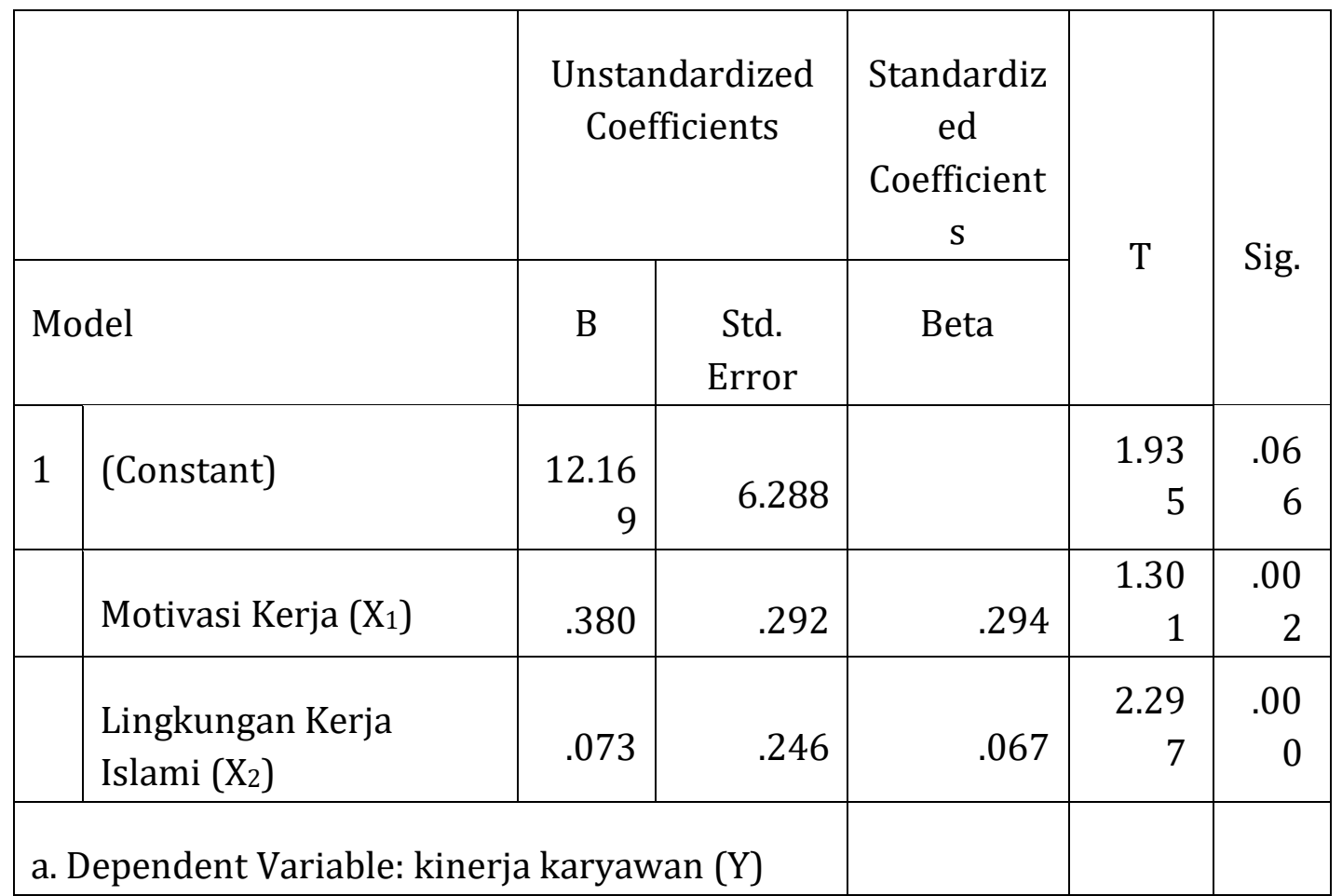

Sumber : Output data yang diolah pada SPSS Versi 23, 2021.

Berdasarkan hasil tabel 8 Uji T yang dilakukan melalui analisis Statistics dengan menggunakan Software SPSS Versi 23. Maka dapat disusun hasil Uji T sebagai berikut:

1) Pengaruh Variabel Motivasi Kerja ( $\mathrm{X}_{1}$ ) terhadap Kinerja Karyawan (Y). Berdasarkan hasil uji t diatas diperoleh nilai thitung variabel Motivasi Kerja $\left(X_{1}\right)$ sebesar 1,301 dengan nilai signifikansi sebesar $0.002<$ 0,05 artinya signifikan. Maka dapat disimpulkan bahwa variabel Motivasi Kerja $\left(\mathrm{X}_{1}\right)$ secara parsial memiliki pengaruh yang signifikan terhadap Kinerja Karyawan (Y). Arah pengaruh bertanda positif yang menunjukkan bahwa semakin luas dan meningkatnya Kompensasi yang didapatkan akan membuat Kinerja Karyawan meningkat. 


\section{Vol 5 No 1 (2022) 96-114 P-ISSN 2620-295 E-ISSN 2747-0490 DOI: 1047467/elmal.v5i1.639}

2) Pengaruh Variabel Lingkungan Kerja Islami $\left(X_{2}\right)$ terhadap Kinerja Karyawan(Y).

Berdasarkan hasil uji t diatas diperoleh nilai thitung variabel Lingkungan Kerja Islami $\left(\mathrm{X}_{2}\right)$ sebesar 2,297 dengan nilai signifikansi sebesar 0,00 $<0,05$ artinya signifikan. Maka dapat disimpulkan bahwa variabel Lingkungan Kerja Islami $\left(\mathrm{X}_{2}\right)$ secara parsial memiliki pengaruh yang signifikan terhadap Kinerja Karyawan (Y). Arah pengaruh bertanda positif yang menunjukkan bahwa meningkatnya Lingkungan Kerja Islami akan membuat Kinerja Karyawan meningkat.

b. Uji Simultan (Uji F)

Uji $\mathrm{F}$ atau analisis simultan ini digunakan untuk mengetahui ada atau tidak adanya pengaruh variabel Independen Motivasi Kerja ( $\left.\mathrm{X}_{1}\right)$ dan Lingkungan Kerja Islami $\left(\mathrm{X}_{2}\right)$ secara serentak atau bersamaan terhadap variabel Dependen Kinerja Karyawan (Y). Hal itu dapat diputuskan dengan melihat hasil dari nilai signifikansi F. Yang apabila nilai signifikansi $\mathrm{F}<$ dari 0,05, maka pengaruh antara variabel Independen (X) secara bersamaan terhadap variabel Dependen (Y). Kemudian jika nilai signifikansi F > dari 0,05, maka tidak ada pengaruh antara variabel Independen (X) secara bersamaan terhadap variabel Dependen (Y).

Tabel 9 Hasil Uji F

ANOVAa

\begin{tabular}{|c|c|c|c|c|c|c|}
\hline \multicolumn{2}{|c|}{ Model } & \multirow{2}{*}{$\begin{array}{r}\text { Sum of Squares } \\
11.606\end{array}$} & \multirow{2}{*}{$\begin{array}{l}\text { Df } \\
2\end{array}$} & \multirow{2}{*}{$\begin{array}{l}\text { Mean } \\
\text { Square } \\
5.803\end{array}$} & \multirow{2}{*}{$\frac{F}{1.338}$} & \multirow{2}{*}{$\begin{array}{l}\text { Sig. } \\
.283^{a}\end{array}$} \\
\hline 1 & $\begin{array}{l}\text { Regressio } \\
\mathrm{n}\end{array}$ & & & & & \\
\hline & Residual & 95.434 & $\begin{array}{l}2 \\
2\end{array}$ & 4.338 & & \\
\hline & Total & 107.040 & $\begin{array}{l}2 \\
4\end{array}$ & & & \\
\hline & pendent V & able: Kinerja Kar & awal & $(\mathrm{Y})$ & & \\
\hline
\end{tabular}

Sumber : Output data yang diolah pada SPSS Versi 23, 2020. 


\section{Vol 5 No 1 (2022) 96-114 P-ISSN 2620-295 E-ISSN 2747-0490 DOI: 1047467/elmal.v5i1.639}

Dari output pada tabel 9 diperoleh nilai $F_{\text {hitung }}$ sebesar 5,803 dengan signifikansi sebesar 0,283. Maka hasil dari signifikansi tersebut adalah 0,283 $<0,05$. Yang artinya terdapat pengaruh secara signifikan antara kedua variabel Independen yaitu Pengaruh Motivasi Kerja ( $\mathrm{X}_{1}$ ) dan Lingkungan Kerja Islami $\left(\mathrm{X}_{2}\right)$ terhadap Kinerja Karyawan (Y) secara serentak atau bersamaan.

c. Uji R R $^{2}$ Koefisiensi Deteminasi)

Uji $\mathrm{R}^{2}$ atau koefisiensi determinasi digunakan untuk mengetahui persentase perubahaan variabel-variabel tidak bebas atau terikat yaitu $(\mathrm{Y})$ yang disebabkan oleh variabel bebas yaitu (X).

Tabel 10 Hasil Uji R2

Model Summaryb

\begin{tabular}{|l|r|r|r|r|}
\hline Model & \multicolumn{1}{|c|}{$\mathrm{R}$} & R Square & $\begin{array}{c}\text { Adjusted R } \\
\text { Square }\end{array}$ & $\begin{array}{r}\text { Std. Error of } \\
\text { the Estimate }\end{array}$ \\
\hline 1 & $.329 \mathrm{a}$ & .308 & .027 & 2.083 \\
\hline
\end{tabular}

a. Predictors: (Constant), lingkungan kerja Islami $\mathrm{x} 2$, motivasi $\mathrm{x} 1$

b. Dependent Variable: kinerja karyawan y

Sumber : Output data yang diolah pada SPSS Versi 23, 2020.

Berdasarkan hasil tabel $10 \mathrm{Uji}^{2}$ atau Koefisiensi Determinasi yang dilakukan melalui analisis Statistics dengan menggunakan Software SPSS Versi 23. Maka dapat dijelaskan hasil Uji $\mathrm{R}^{2}$ sebagai berikut:

Hasil dari pengolahan statistik pengujian $\mathrm{R}^{2}$ atau koefisiensi determinasi menunjukkan bahwa variabel Independen yaitu Motivasi Kerja $\left(\mathrm{X}_{1}\right)$ dan Lingkungan Kerja Islami $\left(\mathrm{X}_{2}\right)$ berhasil mempengaruhi variabel Dependen yaitu Kinerja Karyawan (Y) sebesar 30,8\% sisanya sebesar 69,2\%. Hasil dari Uji $\mathrm{R}^{2}$ atau koefisiensi determinasi tersebut memberikan makna bahwa masih ada variabel Independen lainnya yang dapat mempengaruhi Kinerja Karyawan. 
Vol 5 No 1 (2022) 96-114 P-ISSN 2620-295 E-ISSN 2747-0490 DOI: $1047467 /$ elmal.v5i1.639

\section{KESIMPULAN DAN SARAN}

\section{A. Kesimpulan}

Berdasarkan hasil penelitian yang telah dibahas pada bab sebelumnya mengenai pengaruh Motivasi Kerja dan Lingkungan Kejra Islami terhadap Kinerja Karyawan pada Bank Syariah Indonesia KCP Bogor Pomad, maka dapat ditarik kesimpulan sebagai berikut:

1. Pengaruh Motivasi Kerja memiliki nilai yang signifikan terhadap Kinerja Karyawan pada Bank Syariah Indonesia KCP Bogor Pomad. Hal tersebut dapat dibuktikan dengan nilai thitung sebesar 1.301 dengan nilai signifikansi sebesar $0.002<0,05$ artinya signifikan. Serta memiliki nilai koefisien regresi sebesar 0,380. Maka semakin banyak Motivasi Kerja yang diperoleh dan dimiliki maka akan semakin menumbuhkan semangat Kinerja Karyawan pada Bank Syariah Indonesia KCP Bogor Pomad.

2. Lingkungan Kerja Islami memiliki nilai yang signifikan terhadap Kinerja Karyawan pada Bank Syariah Indonesia KCP Bogor Pomad tersebut dapat dibuktikan dengan nilai thitung sebesar 0.297 dengan nilai signifikansi sebesar $0.000<0,05$ artinya signifikan. Serta memiliki nilai koefisien regresi sebesar 0,073. Maka semakin tinggi dukungan lingkungan kerja yang mendukung maka akan semakin menumbuhkan Kinerja Karyawan pada Bank Syariah Indonesia KCP Bogor Pomad.

3. Pengaruh Motivasi Kerja dan Lingkungan Kerja Islami terhadap Kinerja Karyawan pada Bank Syariah Indonesia KCP Bogor Pomad. Hal tersebut dibuktikan dari hasil regresi linear berganda yang menghasilkan nilai Fhitung sebesar 1.338 dengan signifikansi sebesar 0,283. Maka hasil dari signifikansi tersebut adalah $0,283<0,05$. Yang artinya terdapat pengaruh secara signifikan antara kedua variabel Independen yaitu Pengaruh Motivasi kerja $\left(\mathrm{X}_{1}\right)$ dan Lingukungan kerja Islami $\left(\mathrm{X}_{2}\right)$ terhadap Kinerja Karyawan (Y). Secara individu variable Pengaruh Motivasi kerja memberikan nilai koefisien sebesar 0,380 dan variabel Lingkungan Kerja memberikan nilai koefisien sebesar 0,073 yang berarti mempunyai nilai positif. Maka semakin banyak Motivasi kerja yang diperoleh, dan semakin tinggi fasilitas lingkungan kerja yang nyaman maka akan meningkatkan Kinerja Karyawan pada Bank Syariah Indonesia KCP Bogor Pomad. 
Vol 5 No 1 (2022) 96-114 P-ISSN 2620-295 E-ISSN 2747-0490 DOI: $1047467 /$ elmal.v5i1.639

\section{B. Saran}

Berdasarkan pembahasan dan kesimpulan penelitian diatas maka dapat diberikan beberapa saran sebagai berikut:

1. Bagi pihak pimpinan Bank Syariah Indonesia KCP Bogor Pomad

Penelitian ini diharapkan dapat memberikan kontribusi bagi perusahaan. Hasil penelitian diharapkan dapat memberikan solusi maupun evaluasi terhadap masalah kinerja yang terjadi di perusahaan. Dalam penelitian ini peneliti berharap pemimpin lebih peka terhadap masalah yang dihadapi karyawan seperti mengenai gaji yang diterima, target perusahaan dan dapat meningkatkan motivasi kerja dengan memberikan kejelasan tentang tujuan perusahaan dengan penjelasan secara spesifik dan memberikan solusi tentang pencapaian target. Selanjutnya, dengan adanya lingkungan kerja islami yang diberikan terhadap karyawan akan memacu para karyawan untuk mencapai tingkat kinerja yang lebih tinggi. Perusahaan juga diharapkan lebih menggairahkan cara kerja karyawan serta memberikan dukungan dan dorongan. Terutama kepada karyawan yang telah memiliki motivasi pada diri mereka. Sehingga, diharapkan akan menimbulkan kinerja dari karyawan yang efektif dan efisien agar visi dan misi perusahaan Bank Syariah Indonesia KCP Bogor Pomad tercapai bersama.

2. Bagi karyawan Bank Syariah Indonesia KCP Bogor Pomad

Saran untuk Karyawan Bank Syariah Indonesia KCP Bogor Pomad diharapkan dapat meningkatkan kinerja sehingga tujuan perusahaan dapat dicapai dengan efektif dan efisien. Karyawan Bank Syariah Indonesia KCP Bogor Pomad diharapkan dapat meningkatkan kinerja dan kualitas kerjanya guna mencapai target perusahaan. Dengan menumbuhkan rasa memiliki terhadap perusahaan, maka karyawan diharapkan dapat meningkatkan kinerja dan memaksimalkan pencapaian perusahaan. Dengan demikian, karyawan Bank Syariah Indonesia KCP Bogor Pomad diharapkan dapat menentukan tujuan kerjanya sendiri dan peduli terhadap pekerjaannya. Hal ini dapat meningkatkan motivasi dalam diri karyawan. 
Vol 5 No 1 (2022) 96-114 P-ISSN 2620-295 E-ISSN 2747-0490 DOI: 1047467/elmal.v5i1.639

\section{DAFTAR PUSTAKA}

Andi Ibrahim, Asrul Haq Alang, Madi, Baharuddin, M. A. A., \& Darmawati. (2018). Metodelogi penelitian (G. Ilmu (ed.); 1st ed.).

Anoraga, B., \& Prasetyo, A. (2015). Motivasi Kerja Islam dan Etos Kerja Islam Karyawan Bank Jatim Syariah Cabang Surabaya. Jurnal Ekonomi Syariah $\begin{array}{llll}\text { Teori Dan Terapan, } & 2(7),\end{array}$ https://doi.org/10.20473/vol2iss20157pp531-541

Devi Abrista dan Tanjung Hendri. (2013). Metodologi Penelitian.

Enny, W. M. (2019). Manajemen Sumber Daya Manusia. http://eprints.ubhara.ac.id/424/31/Buku-MSDM-2019.pdf

Farida umi, H. sri. (2015). Manajemen sumber daya manusia II. In FEBS Letters (Vol. 185, Issue 1). Umpo press. https://doi.org/10.1016/00145793(85)80729-8

Fitria, T. N. (2016). Kontribusi Ekonomi Islam Dalam Pembangunan Ekonomi Nasional. Jurnal Ilmiah Ekonomi Islam, 2(03), 29-40. https://doi.org/10.29040/jiei.v2i03.3

Maguni, W., \& Maupa, H. (2018). Teori Motivasi, Kinerja, dan Prestasi Kerja dalam Al-Quran Serta Fleksibilitas Penerapannya pada Manajemen Perbankan Islam. Jurna Studi Ekonommi Dan Bisnis Islam, 3(1 juni), 100124.

NiKurniasari, R. (2018). Pemberian Motivasi serta Dampaknya Terhadap Kinerja Karyawan Pada Perusahaan Telekomunikasi Jakarta. Widya Cipta, 2(1), 32-39. 